of this was buried in a thick file of case notes. Patients who do not report histories of childhood sexual abuse spontaneously do so with surprising willingness when questioned directly, ${ }^{5}$ and an interview with a female social worker is a particularly suitable strategy..$^{23}$

Patients like those we have studied present a particular challenge to psychiatry because they are often difficult to help. Guilt, alienation, and despair are often deep ${ }^{12}$ and lead to resistance against psychiatric intervention. Direct confrontation about symptoms that cannot be assessed objectively may destroy any chance of a therapeutic relationship. We found that psychiatric help coincided with a temporary reduction in the rate of physical investigations but failed to prevent a gradual relapse of symptoms. Therefore, while referral to a psychiatrist is appropriate, general practitioners, physicians, and surgeons must forestall further referral, investigation, and intervention. Once the pattern has been identified such interventions should be contemplated only in the light of objectively measurable signs or the probability of disease occurring that threatens life or health. Intervention solely to alleviate symptoms should be resisted.

We thank Dr Glin Bennet for permission to report on two of his patients, and Mrs Joan Sparks for help in the literature search.

1 Markowe HLJ. The frequency of childhood sexual abuse in the UK. Health Trends 1988; Feb:2-6.

2 Russell DEH. The secret trauma: incest in the lives of girls and women. New York: Basic Books, 1986

West DJ. Incest in childhood and adolescence: long term effects and therapy. Br f Hosp Med 1988;40:352-60.
4 Mrazek D, Mrazek P. Child maltreatment. In: Rutter RM, Hertzov L, eds. Child and adolescent psychiatry. Oxford: Blackwell Scientific, 1985:691-3. 5 Rosenfeld AA. Incidence of a history of incest among 18 female psychiatric patients. Am f Psychiatry 1979;136:791-5.

6 Gold ER. Long-term effects of sexual victimization in childhood: an attributional approach. $\mathcal{F}$ Consult Clin Psychol 1986;54:471-5.

7 Wuitchik M, Bakal D, Lipshitz J. The clinical significance of pain and cognitive activity in latent labor. Obstet ( ivnecol 1989;73:35-42.

LaFerla JJ. Psvchologic and behavioral factors in hyperemesis gravidarum. Am $\mathcal{F}$ Obstet Gynecol 1988;159:532-3.

9 Burges Watson IP, Hoffman L, Wilson GV. The neuropsichiatry of post-traumatic stress disorder. Brf Psychiutry 1988:152:164-73.

10 Ellenson GS. Detecting a history of incest: a predictive syndrome. Social Casework 1985:66:525-32.

11 Cohen ME, Robins E, Purtell JJ, Altman MW, Reid DE. Excessive surgery in hysteria: study of surgical procedures in 50 women with hysteria and 190 hysteria: study of surgical proce

12 Sedney MA, Brooks B. Factors associated with a history of childhood sexual experience in a non-clinical female population. Fournal of the American Academy of Child Psychiatry 1984;23:215.

13 Lindberg FH, Distad LJ. Post traumatic stress disorders in women who experienced childhood incest. Child Abuse Negl 1985;9:329.

14 Briere J, Runtz. M. Symptomatology associated with childhood sexual victimization in a non-clinical adult sample. Child Abuse Negl 1988:12:51-9. 5 Morrison J. Childhood sexual histories of women with somatisation disorder. Am O Psychiatry 1989;146:239-41.

16 Raskin D. Diagnosis in patients with chronic pelvic pain. Am f Psychiatry 1984;141:824.

17 Walker E, Katon W, Harrop-Griffiths J, Holm L, Russo J, Hickok LR. Relationship of chronic pelvic pain to psychiatric diagnosis and childhood Relations

18 Rosenfeld AA, Nadelson CC, Kreiger M, Backman JH. Incest and sexual abuse in children. Fournal of the American Academy of Child Psychiatry

19 Herman JL, Schatzow E. Recovery and verification of memories of childhood sexual trauma. Psychoanalytic Psychology 1987;4:1-14

20 Brown A. Initial and long-term effects: a review of the research, In: Finkelhor $\mathrm{D}$, ed. A sourcebook on childhood sexual abuse. Beverly Hills, California: Sage, 1986:165-75.

21 Eisendrath SJ, Way LW, Ostroff JW, Johanson CA. Identification of psychogenic abdominal pain. Psychosomatics 1986;27:705-12.

22 Bachmann GA, Moeller TP, Benett J. Childhood sexual abuse and the consequences in adult women. Childhood Sexual Abuse 1988;71:631-41.

23 Caldirola D, Gemperle MB, Guzinski GM, Gross RJ, Doerr H. Incest and pelvic pain: the social worker as part of a research team. Health Soc Work 1983;3:309-19.

(Accepted 19 January 1990)
Biomedical Sciences

Research Centre

University of Ulster,

Jordanstown, County

Antrim BT37 0QB

M B E Livingstone, MSC,

lecturer

J J Strain, PHD, senior

lecturer

M E Barker, PHD, nutritionist

PG McKenna, PHD, professor

MRC Dunn Nutrition Unit, Cambridge CB4 IXJ

A M Prentice, PHD, senior scientist

W A Coward, PHD, senior scientist

A E Black, BSC, chief research officer

R G Whitehead, PHD, director

Correspondence and requests for reprints to: Ms Livingstone.

Br.Med f 1990;300:708-12

\title{
Accuracy of weighed dietary records in studies of diet and health /
}

M B E E Livingstone, A M Prentice, J J Strain, W A Coward, A E 1 Black, M E Barker, P G McKenna,
R G Whitehead

Abstract

Objective - To provide an independent evaluation of seven day weighed dietary records, which are currently accepted as the most, accurate technique for assessing habitual dietary intake in studies investigating the links between diet and health.

Design-Subjects who had previously participated in the Northern Ireland diet and health study were reselected by stratified random sampling to represent the range of energy intakes in the study as assessed by the seven day weighed dietary record.

Setting-Northern Ireland.

Subjects-31 Free living adults (16 men and 15 women).

Main outcome measures-Energy intake as measured by the seven day weighed dietary record and total energy expenditure estimated concurrently by the doubly labelled water technique.

Results-Average recorded energy intakes were significantly lower than measured expenditure in the group overall $(9.66 \mathrm{MJ} /$ day $v 12.15 \mathrm{MJ} /$ day, $95 \%$ confidence interval 1.45 to $3.53 \mathrm{MJ} / \mathrm{day}$ ). Among those in the upper third of energy intakes the mean (SE) ratio of intake to expenditure was close to $1 \cdot 0$, indicating accurate records (men $1.01(0 \cdot 11)$, women $0.96(0.08))$. In the middle and lower thirds the ratios for men were only $0.74(0.05)$ and $0.70(0.07)$ respectively and for women $0.89(0.07)$ and 0.61 $(0 \cdot 07)$.

Conclusions - These results show a serious bias in reporting habitual energy intake. If substantiated they may have wide implications for the interpretation of many nutritional studies.

\section{Introduction}

Many studies of diet ånd health depend on accurate assessments of habitual intakes of food and nutrients in free living populations. Unfortunately, it has often been assumed that collecting such data is straightforward, and there has been a tendency to focus greater effort and resources on defining the correlates of health state with greater accuracy. Shortcomings in the methodology of dietary surveys may therefore have resulted in many potentially misleading data being published and may have contributed to the widespread confusion about the impact of diet on health. Recently there has been a growing awareness that measuring food intake may in fact be the most challenging problem faced in these studies. ${ }^{12}$

Difficulties in measuring food intake can be considered in three main categories: precision, random inaccuracy, and bias. The precision of dietary measurements can be readily assessed and thus allowed for when determining sample size or analysing results. ${ }^{3}$ Random inaccuracy may lead to false negative conclusions in epidemiological studies by reducing true associations but will not generate misleading correlations. Non-random errors, or bias, therefore emerge as the most serious problem. Although bias is recognised, its magnitude and direction has usually remained undetected as until recently there were no tech- 
niques to verify the methodology of dietary surveys.

The method of measuring energy expenditure that uses doubly labelled water provides an independent and objective means of validating data on dietary intake provided that subjects are in energy balance. It has been used to show serious bias in food records from obese subjects. ${ }^{+}$We used it to evaluate suspiciously low energy intakes recorded by a randomly selected population of adults in Northern Ireland using seven day weighed dietary records.

\section{Subjects and methods}

We studied some of the subjects who had participated in the Northern Ireland diet and health study, which assessed the intake of energy and nutrients of 592 randomly selected adults by seven day weighed dietary records (mean (SD) energy intake for men= $10.6(2 \cdot 4) \mathrm{MJ} /$ day $(\mathrm{n}=258)$ and for women=7.1 (1.9) $\mathrm{MJ} /$ day $(\mathrm{n}=334)) .^{5}$ We used a random stratified sampling procedure to reselect subjects representing the wide range of intakes observed in the initial survey; as in all large-scale epidemiological dietary surveys the data included several low energy intakes. Seventy six subjects were invited by letter to join the current study, and 31 ( 16 men, 15 women) agreed to participate after follow up interviews. The rate of cooperation was related to the subjects' energy intakes, averaging $60 \%$ for those whose intake was greater than the mean and only $32 \%$ for those with intakes below the mean. The final group (table I) represented a wide range of ages, occupations, and socioeconomic status. Some of the subjects had jobs that required manual activity, but most were in predominantly sedentary jobs. All but three of the subjects undertook regular physical exercise, often of medium to high intensity.

Ten subjects were marginally obese (grade I, body mass index $25-30 \mathrm{~kg} / \mathrm{m}^{2}$ ) and three subjects had grade II obesity (body mass index $30-40 \mathrm{~kg} / \mathrm{m}^{2}$ ) according to the Garrow classification. ${ }^{6}$
SEVEN DAY WEIGHED DIETARY RECORDS

For seven consecutive days each subject recorded the weight of items of food and fluid consumed and of leftovers. Subjects were issued with dietary scales (Miniscale P C International, Cambridge; $2000 \times 1$ g); a logbook for recording foods and fluids eaten at home or prepared at home for consumption elsewhere; a pocket notebook for recording foods and fluids obtained and eaten away from home; and written instructions, which included examples of completed forms. The day before recording started each subject was given a detailed explanation and shown the cumulative weighing technique and then repeated the procedure in the presence of the investigator to ensure that he or she was competent in the technique. We visited subjects daily to collect samples of urine for the doubly labelled water test, and we also monitored subjects' progress in weighing food and checked their records for completeness and accuracy.

Subjects were instructed to record brand names of foods and to provide a complete description of the method of preparation, cooking, and recipes for composite dishes; the records were used to adjust for losses during cooking. For foods and fluids eaten away from home we requested a description of the food, place of purchase, and price. When possible we bought and weighed corresponding portions of the food, but if this was not feasible we substituted estimated weights of the food based on the portions eaten at home or average figures for portions. In some cases subjects volunteered to weigh food away from home, and this practice was encouraged if the investigator was reassured that it would not interfere with the subject's usual eating habits. The intake of metabolisable energy was calculated from a computerised version of McCance and Widdowson's The Composition of Foods, which included supplementary data. ${ }^{10}$

THE DOUBLY LABELLED WATER METHOD

The doubly labelled water $\left({ }^{2} \mathrm{H}_{2}{ }^{18} \mathrm{O}\right)$ method assesses

TABLE I - Description of subjects participating in study of energy intake and expenditure

\begin{tabular}{|c|c|c|c|c|c|c|c|}
\hline Case No & Occupation & Social class ${ }^{\star}$ & $\begin{array}{c}\text { Age } \\
\text { (years) }\end{array}$ & $\begin{array}{c}\text { Height } \\
(\mathrm{m})\end{array}$ & $\begin{array}{l}\text { Weight } \\
(\mathrm{kg})\end{array}$ & $\begin{array}{c}\% \text { Of ideal } \\
\text { body weight }\end{array}$ & $\begin{array}{c}\text { Body mass } \\
\text { index } \\
\left(\mathrm{kg} / \mathrm{m}^{2}\right)\end{array}$ \\
\hline \multicolumn{8}{|c|}{ Men } \\
\hline 1 & Unemployed & & 30 & $1 \cdot 76$ & $91 \cdot 0$ & 131 & $29 \cdot 4$ \\
\hline 2 & Construction labourer & IV & 32 & $1 \cdot 79$ & $88 \cdot 2$ & 124 & $27 \cdot 6$ \\
\hline 3 & Architectural technician & III (Non-manual) & 27 & $1 \cdot 72$ & $68 \cdot 2$ & 104 & $23 \cdot 2$ \\
\hline 4 & Policeman & III (Non-manual) & 25 & $1 \cdot 80$ & $111 \cdot 4$ & 155 & $34 \cdot 4$ \\
\hline 5 & General duties assistant in electricity service & IV & 29 & 1.72 & $71 \cdot 0$ & 108 & $24 \cdot 1$ \\
\hline 6 & Retail manager & II & 28 & $1 \cdot 77$ & $77 \cdot 5$ & 111 & $24 \cdot 8$ \\
\hline 7 & Clerical officer & III (Non-manual) & 32 & 1.74 & $76 \cdot 5$ & 112 & $25 \cdot 4$ \\
\hline 8 & Management consultant & I & 46 & 1.77 & $82 \cdot 7$ & 118 & $26 \cdot 5$ \\
\hline 9 & Sales executive & II & 41 & 1.67 & $65 \cdot 5$ & 101 & $23 \cdot 5$ \\
\hline 10 & Systems analyst & II & 44 & $1 \cdot 70$ & $82 \cdot 7$ & 125 & $28 \cdot 6$ \\
\hline 11 & Shop decorator and fitter & IV & 30 & 1.82 & $76 \cdot 8$ & 105 & $23 \cdot 3$ \\
\hline 12 & Company director & II & 33 & 1.68 & $65 \cdot 5$ & 100 & $23 \cdot 3$ \\
\hline 13 & Architectural technician & III (Non-manual) & 30 & 1.93 & $79 \cdot 1$ & 97 & $21 \cdot 3$ \\
\hline 14 & Fireman & III (Non-manual) & 32 & 1.75 & $81 \cdot 8$ & 119 & $26 \cdot 7$ \\
\hline 15 & Student (full time) & & 17 & $1 \cdot 72$ & $67 \cdot 3$ & 102 & $22 \cdot 9$ \\
\hline 16 & Policeman & III (Non-manual) & 28 & $1 \cdot 82$ & $90 \cdot 0$ & 123 & $27 \cdot 3$ \\
\hline \multicolumn{2}{|c|}{ Mean (SD) } & & $31 \cdot 5(7 \cdot 2)$ & $1 \cdot 76(0.06)$ & $79 \cdot 7(11.9)$ & $115(15)$ & $25 \cdot 8(3 \cdot 3)$ \\
\hline \multicolumn{8}{|c|}{ Women } \\
\hline 17 & School meals assistant & III (Non-manual) & 42 & 1.58 & $65 \cdot 5$ & 117 & $26 \cdot 1$ \\
\hline 18 & Cleaner & $\mathrm{V}$ & 50 & 1.56 & $59 \cdot 6$ & 108 & $24 \cdot 5$ \\
\hline 19 & Teacher of clinical staff & II & 28 & 1.67 & $59 \cdot 5$ & 98 & $21 \cdot 4$ \\
\hline 20 & Housewife & III (Manual) & 37 & $1 \cdot 60$ & $59 \cdot 0$ & 103 & $23 \cdot 0$ \\
\hline 21 & Housewife & III (Non-manual) & 53 & 1.56 & $61 \cdot 1$ & 122 & $27 \cdot 6$ \\
\hline 22 & Company cashier & III (Non-manual) & 46 & $1 \cdot 64$ & $68 \cdot 2$ & 116 & $25 \cdot 5$ \\
\hline 23 & Librarian (part time) & II & 31 & 1.53 & $53 \cdot 6$ & 100 & $22 \cdot 9$ \\
\hline 24 & Housewife & II & 34 & 1.60 & $46 \cdot 8$ & 82 & $18 \cdot 3$ \\
\hline 25 & Teacher & II & 36 & 1.59 & $75 \cdot 9$ & 135 & $30 \cdot 0$ \\
\hline 26 & Nurse & II & 21 & 1.63 & $62 \cdot 7$ & 107 & $23 \cdot 6$ \\
\hline 27 & Student (full time) & & 22 & $1 \cdot 64$ & $60 \cdot 0$ & 102 & $22 \cdot 4$ \\
\hline 28 & Shop and bar assistant (part time) & III (Non-manual) & 26 & 1.64 & $80 \cdot 4$ & 137 & $30 \cdot 0$ \\
\hline 29 & Assembly line worker & IV & 20 & 1.67 & $62 \cdot 5$ & 103 & $22 \cdot 5$ \\
\hline 30 & Nurse (part time) & I & 54 & 1.56 & $57 \cdot 3$ & 104 & $23 \cdot 5$ \\
\hline 31 & Housewife & II & 32 & $1 \cdot 66$ & $63 \cdot 6$ & 105 & $23 \cdot 2$ \\
\hline \multicolumn{2}{|c|}{ Mean (SD) } & & $35 \cdot 5(11 \cdot 4)$ & $1.61(0.04)$ & $62 \cdot 4(8 \cdot 2)$ & $109(14)$ & $24 \cdot 3(3 \cdot 1)$ \\
\hline
\end{tabular}

${ }^{\star}$ Classification of the Office of Population Censuses and Surveys. 
the rate of production of carbon dioxide by measuring the differential disappearance of the stable isotopes deuterium and oxygen-18 after subjects have been given an oral loading dose of labelled water. We calculated total energy expenditure from carbon dioxide production using classic respirometry formulas in which values for the respiratory quotient are derived from the composition of the diet." The method measures energy expenditure integrated over the entire period of measurement ( 15 days in this study). It is safe, non-invasive, and non-intensive as subjects need only drink one dose and collect a urine sample in the middle of each subsequent morning. Ten cross validation studies of 149 subjects in several different laboratories indicated that the method is accurate to $\pm 2-3 \% .{ }^{1213}$ The accuracy depends on the exact method

TABLE II - Estimates of energy intake and expenditure and basal metabolic rate

\begin{tabular}{|c|c|c|c|c|c|c|}
\hline \multirow[b]{2}{*}{ Case No } & \multirow[b]{2}{*}{$\begin{array}{c}\text { Mean energy } \\
\text { intake during } \\
\text { previous study } \\
(\mathrm{MJ} / \text { day })\end{array}$} & \multicolumn{5}{|c|}{ Present study } \\
\hline & & $\begin{array}{l}\text { Mean energy } \\
\text { intake } \\
(\mathrm{MJ} / \text { day })\end{array}$ & $\begin{array}{c}\text { Basal metabolic } \\
\text { rate } \\
(\mathrm{MJ} / \mathrm{day})\end{array}$ & $\begin{array}{l}\text { Total energy } \\
\text { expenditure } \\
\text { (MJ/day) }\end{array}$ & $\begin{array}{l}\text { Energy intake/ } \\
\text { basal metabolic } \\
\text { rate }\end{array}$ & $\begin{array}{c}\text { Energy intake/ } \\
\text { total energy } \\
\text { expenditure }\end{array}$ \\
\hline \multicolumn{7}{|c|}{ Men } \\
\hline 1 & $16 \cdot 23$ & $16 \cdot 38$ & $9 \cdot 50$ & $15 \cdot 62$ & $1 \cdot 72$ & 1.05 \\
\hline 2 & $12 \cdot 01$ & $11 \cdot 17$ & $8 \cdot 43$ & $21 \cdot 71$ & 1.33 & 0.51 \\
\hline 3 & $9 \cdot 65$ & 9.91 & $6 \cdot 68$ & $12 \cdot 44$ & 1.48 & 0.80 \\
\hline 4 & 8.93 & $13 \cdot 20$ & $9 \cdot 67$ & 15.69 & $1 \cdot 37$ & 0.84 \\
\hline 5 & 11.75 & 10.00 & $7 \cdot 03$ & 13.98 & 1.42 & 0.72 \\
\hline 6 & $11 \cdot 12$ & $13 \cdot 24$ & $7 \cdot 39$ & $16 \cdot 52$ & 1.79 & 0.80 \\
\hline 7 & 8.57 & 8.85 & $6 \cdot 71$ & $11 \cdot 17$ & 1.32 & 0.79 \\
\hline 8 & $11 \cdot 47$ & $11 \cdot 28$ & $7 \cdot 34$ & $13 \cdot 27$ & 1.54 & 0.85 \\
\hline 9 & $10 \cdot 22$ & $8 \cdot 25$ & 6.84 & $9 \cdot 87$ & $1 \cdot 21$ & 0.84 \\
\hline 10 & $10 \cdot 38$ & $9 \cdot 01$ & $7 \cdot 56$ & $15 \cdot 38$ & $1 \cdot 19$ & 0.59 \\
\hline 11 & $19 \cdot 62$ & $12 \cdot 11$ & $7 \cdot 73$ & $16 \cdot 08$ & 1.57 & 0.75 \\
\hline 12 & 11.89 & $13 \cdot 14$ & $6 \cdot 30$ & $9 \cdot 36$ & 2.09 & 1.40 \\
\hline 13 & $13 \cdot 25$ & 14.58 & $7 \cdot 13$ & $15 \cdot 24$ & $2 \cdot 04$ & 0.96 \\
\hline 14 & 4.88 & 7.03 & $7 \cdot 59$ & $15 \cdot 18$ & 0.93 & 0.46 \\
\hline 15 & $8 \cdot 28$ & 10.03 & $7 \cdot 23$ & 13.00 & 1.39 & 0.77 \\
\hline 16 & $10 \cdot 40$ & $11 \cdot 23$ & $7 \cdot 87$ & $13 \cdot 16$ & 1.43 & 0.85 \\
\hline $\begin{array}{c}\text { Mean } \\
(\mathrm{SD})\end{array}$ & $11 \cdot 16(3 \cdot 34)$ & $11 \cdot 21(2 \cdot 48)^{\star}$ & $7.56(0.94)$ & $14.23(2.95)$ & $1.49(0.30)$ & $0.81(0.22)$ \\
\hline
\end{tabular}

\begin{tabular}{|c|c|c|c|c|c|c|}
\hline \multicolumn{7}{|c|}{ Women } \\
\hline 17 & 8.62 & $8 \cdot 02$ & $5 \cdot 36$ & $10 \cdot 01$ & 1.50 & 0.80 \\
\hline 18 & 6.48 & $7 \cdot 63$ & 5.33 & 11.02 & 1.43 & 0.69 \\
\hline 19 & $11 \cdot 67$ & $11 \cdot 49$ & $6 \cdot 10$ & 11.97 & 1.88 & 0.96 \\
\hline 20 & 7.98 & $9 \cdot 40$ & 5.75 & 9.33 & 1.63 & 1.01 \\
\hline 21 & 5.92 & $7 \cdot 73$ & $4 \cdot 68$ & $7 \cdot 78$ & 1.65 & 0.99 \\
\hline 22 & $7 \cdot 51$ & $10 \cdot 81$ & 6.03 & $11 \cdot 18$ & 1.79 & 0.97 \\
\hline 23 & 6.61 & $7 \cdot 88$ & 4.84 & $7 \cdot 59$ & 1.63 & 1.04 \\
\hline 24 & $7 \cdot 01$ & $8 \cdot 84$ & 5.01 & $7 \cdot 51$ & 1.76 & $1 \cdot 18$ \\
\hline 25 & $5 \cdot 20$ & $5 \cdot 23$ & 5.96 & $11 \cdot 37$ & 0.88 & 0.46 \\
\hline 26 & 8.99 & 8.35 & $5 \cdot 39$ & 9.89 & 1.55 & 0.84 \\
\hline 27 & 8.83 & $7 \cdot 69$ & 5.64 & $9 \cdot 74$ & 1.36 & 0.79 \\
\hline 28 & $7 \cdot 13$ & 8.40 & 6.61 & 12.38 & 1.27 & 0.68 \\
\hline 29 & $4 \cdot 77$ & $5 \cdot 84$ & 6.00 & 8.97 & 0.97 & 0.65 \\
\hline 30 & $4 \cdot 30$ & $4 \cdot 27$ & $5 \cdot 28$ & $9 \cdot 54$ & 0.81 & 0.45 \\
\hline 31 & $9 \cdot 26$ & $8 \cdot 36$ & $6 \cdot 20$ & $10 \cdot 60$ & 1.35 & 0.79 \\
\hline $\begin{array}{l}\text { an } \\
\text { SD) }\end{array}$ & $7.35(1.95)$ & $8.00(1.88) \dagger$ & $5.61(0.55)$ & $9.93(1.53)$ & $1.43(0.33)$ & $0.82(0.21)$ \\
\hline
\end{tabular}

*Confidence interval between the two studies $=-1.33$ to $1.43 \mathrm{MJ} / \mathrm{day}$

tConfidence interval between the two studies $=-0 \cdot 05$ to $+1 \cdot 34 \mathrm{MJ} /$ day.

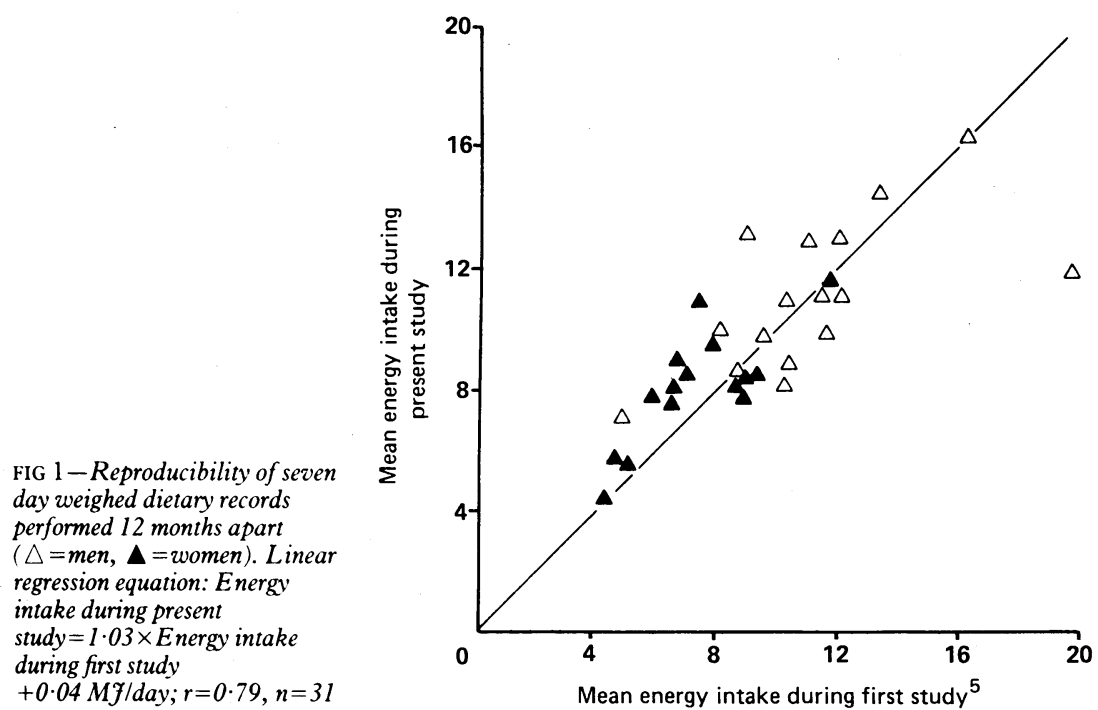

but has been estimated to be better than $\pm 5 \%$ in our laboratory under optimal conditions. ${ }^{1+15}$

Further details of the technique together with methods of analysis, calculation of results, assumptions of fractionation and respiratory quotient, and estimates of error are given elsewhere. ${ }^{+1+16}$ The proportion of labelled water turnover subject to isotopic fractionation was predicted to be 29 (SD 5) $\%$ in men and $32(6) \%$ in women. Propagation of error analysis yielded an average standard error for the estimates of total energy expenditure of 6.0 (SD 2.9)\%.

No attempt was made to assess changes in body stores during the period of isotope measurement as the techniques for analysing body composition are insufficiently precise to give meaningful results when comparing serial measurements over periods as short as 15 days in subjects expected to remain close to energy balance. ${ }^{17}$

\section{BASAL METABOLIC RATE}

Basal metabolic rate was measured under standard conditions with the subject lying in a comfortably warm room, at complete rest, and having fasted for 13 hours. Immediately the subjects woke their rate of exchange of respiratory gases was measured at one minute intervals for 40 minutes by indirect colorimetry (Mijnhardt Oxycon-4/Apple 11 computer test system) with a dry gas meter paramagnetic oxygen analyser, infrared carbon dioxide analyser, and electronic microprocessor system (Cardiokinetics, Medical Diagnostic Instrumentation, Salford, England). One man (case 11) was unable to have his basal metabolic rate measured directly and it was therefore calculated from standard equations based on weight. ${ }^{18}$

The study was approved by the Queen's University ethical committee, Belfast.

\section{Results}

REPRODUCIBILITY OF MEASUREMENTS OF INTAKE

Table II summarises each subject's energy intake during the previous study and this study. The range of intakes remained the same in the women (4.30-11.67 MJ/day; coefficient of variation $27 \% v$ $4 \cdot 27-11 \cdot 49 \mathrm{MJ} /$ day; $24 \%$ ) but was lower in the present study than in the first study among the men (4.88-19.62 MJ/day; $30 \%$ v 7.03-16.38 MJ/day; $22 \%$ ).

Figure 1 shows the moderately high degree of reproducibility of the individual measurements $(r=0 \cdot 79)$. The slope and intercept of the regression line were not significantly different from unity and zero respectively. This is surprising as the stratified sampling protocol, which deliberately selected a disproportionate number of subjects with intakes at the extremes of the range, would be expected to produce appreciable regression towards the mean and give a slope of less than one.

CROSS VALIDATION AGAINST EXPENDITURE OF ENERGY

The mean energy intake during this study was significantly lower than the estimate of energy expenditure in both men $(11 \cdot 21 v 14.23 \mathrm{MJ} /$ day, $95 \%$ confidence interval 1.24 to $4.80 \mathrm{MJ} /$ day $)$ and women $(8.00 \mathrm{v}$ $9.93 \mathrm{MJ} /$ day, 0.74 to $3.12 \mathrm{MJ} /$ day).

Figure 2 shows the data divided into thirds of energy intake. The ratio of energy intake to expenditure was close to 1.0 in the upper third of the results (men 1.01 (SE 0.11), women $0.96(0.08)$ ), indicating no significant bias between the two measurements. The standard errors of these estimates were consistent with the known imprecision of the two measurements; we calculated the standard error for energy intake from the day to day standard deviation of $\pm 25 \%$, which gave a precision over seven days of $\pm 9 \cdot 5 \%(25 \div \sqrt{7})$. The 


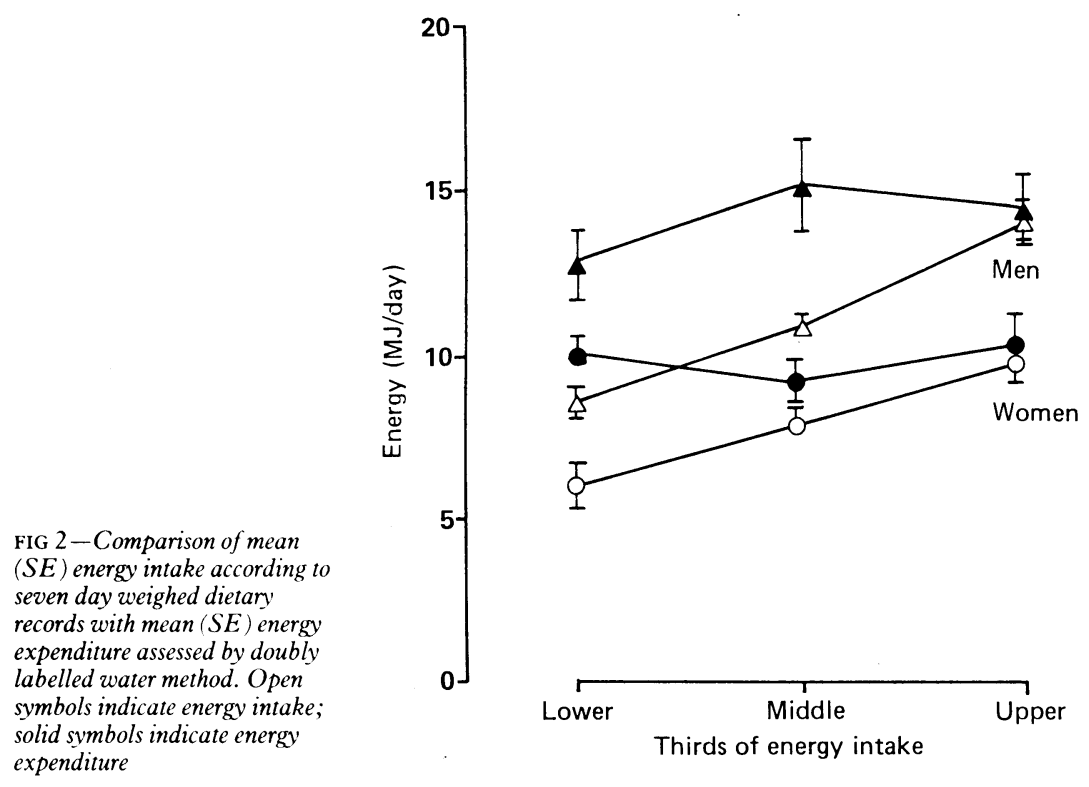

TABLE III-Difference between energy intake and expenditure among individual subjects divided into thirds of energy intake

\begin{tabular}{|c|c|c|c|c|}
\hline & \multicolumn{2}{|r|}{ Men } & \multicolumn{2}{|r|}{ Women } \\
\hline & Case No & $\begin{array}{l}\text { Actual (\%) } \\
\text { difference } \\
(\mathrm{MJ} / \text { day })\end{array}$ & Case No & $\begin{array}{c}\text { Actual }(\%) \\
\text { difference } \\
(M \mathrm{~J} / \text { day })\end{array}$ \\
\hline Lower third & $\begin{array}{r}3 \\
7 \\
9 \\
10 \\
14\end{array}$ & $\begin{array}{l}-2.53(-20) \\
-2.32(-21) \\
-1.62(-16) \\
-6 \cdot 37(-41) \\
-8 \cdot 15(-54)\end{array}$ & $\begin{array}{l}18 \\
25 \\
27 \\
29 \\
30\end{array}$ & $\begin{array}{l}-3 \cdot 39(-31) \\
-6 \cdot 14(-54) \\
-2 \cdot 05(-21) \\
-3 \cdot 13(-35) \\
-5 \cdot 27(-55)\end{array}$ \\
\hline Middle third & $\begin{array}{r}2 \\
5 \\
8 \\
8 \\
11 \\
15 \\
16\end{array}$ & $\begin{array}{r}-10.54(-49) \\
-3.98(-29) \\
-1.99(-15) \\
-3.97(-25) \\
-2.97(-23) \\
-1.93(-15)\end{array}$ & $\begin{array}{l}17 \\
21 \\
23 \\
26 \\
31\end{array}$ & $\begin{array}{l}-1 \cdot 99(-20) \\
-0 \cdot 05(-1) \\
+0 \cdot 29(+4) \\
-1 \cdot 54(-16) \\
-2 \cdot 24(-21)\end{array}$ \\
\hline Upper third & $\begin{array}{r}1 \\
4 \\
6 \\
12 \\
13\end{array}$ & $\begin{array}{l}+0 \cdot 76(+5) \\
-2 \cdot 49(-16) \\
-3 \cdot 28(-20) \\
+3 \cdot 78(+40) \\
-0.66(-4)\end{array}$ & $\begin{array}{l}19 \\
20 \\
22 \\
24 \\
28\end{array}$ & $\begin{array}{l}-0 \cdot 48(-4) \\
+0 \cdot 07(+1) \\
-0 \cdot 37(-3) \\
+1 \cdot 33(+18) \\
-3 \cdot 98(-32)\end{array}$ \\
\hline
\end{tabular}

precision for energy expenditure was estimated at $\pm 6 \%$, giving a combined error of $\pm 11 \%$.

In the middle and lower thirds of energy intake the ratios of energy intake to expenditure were only 0.74 $(\mathrm{SE} 0.05)(\mathrm{p}<0.05)$ and $0.70(0.07)(\mathrm{p}<0.05)$ for men and $0.89(0.05)(\mathrm{p}<0.05)$ and $0.61(0.07)(\mathrm{p}<0.01)$ for women, indicating significant discrepancies.

Table III shows differences between energy intake and expenditure for each subject. When considered individually in this way measurements from 19 of the 31 subjects came within the known limits of precision for the comparison ( $\pm 2 \mathrm{SD}$ at $11 \%$ derived as above and could not by themselves be inaccurate. When the measurements were viewed collectively, however, the overall bias was clearly evident, being more than $20 \%$ in 18 subjects and as much as $50 \%$ in three subjects.

\section{ENERGY INTAKES COMPARED WITH BASAL METABOLIC RATE}

Whole body calorimetry on sedentary subjects has shown that on average the minimum energy expenditure compatible with normal life is about 1.30 times the basal metabolic rate. ${ }^{16}$ Applying this criterion to our subjects suggested that their mean energy intake $(1.49$ and $1.43 \times$ basal metabolic rate for men and women respectively) was probably unrepresentative of their long term energy intake in view of their reasonably active lifestyles.

\section{Discussion}

Many dietary surveys have reported very low intakes of energy and nutrients in substantial subgroups of their study populations. These results are usually justified by proposing the existence of metabolic adaptations that save energy or increase the efficiency of absorption and retention of nutrients to maintain homoeostasis. Scepticism is increasing about the validity of some of these reported energy intakes because of an improved understanding of energy requirements. Physiologists now have a different perspective on data on energy intake from that of dietitians and epidemiologists, who often do not appreciate that some of their results are so low as to be physiologically impossible and therefore their data must be unrepresentative of habitual food intake.

More problematic, however, is the credibility of results that are suspiciously but not unbelievably low. Bias in this case cannot be assessed on the basis of minimal obligatory energy requirements, and cross validation against some other objective measure of intake is necessary.

Our use of doubly labelled water as a reference test detected serious discrepancies between estimates of energy intake and expenditure. This raises several important questions. Firstly, did the error occur in the estimation of energy intake or expenditure? Secondly, if it occurred in the estimation of energy intake were the results spurious or could they have general implications for dietary surveys? Finally, might biased results be identifiable so that epidemiological sets could be edited before further analysis?

In considering errors of assessment the doubly labelled water technique is most open to questions about accuracy as it has only recently been adopted for use in humans. The method has been cross validated in several laboratories against indirect calorimetry, and none of the studies has indicated any significant bias. When data from all of these studies are combined the results suggest a small overestimation of expenditure, but only by $2-3 \% .^{22}$ Other errors may occur outside the controlled conditions of a validation study - for example, when making assumptions about corrections for isotopic fractionation, respiratory quotient, and sequestration or liberation of isotope from metabolic pools other than total body water. The likely limits of error and bias in the method have been assessed by making "worst case" guesses for these assumptions and calculating their impact on the final estimate of energy expenditure. ${ }^{131+}$ This propagation of error analysis shows that the doubly labelled water method is robust and unlikely to be biased by more than $5 \% .{ }^{12-15}$ The results of our study are supported by simultaneous measurements of energy expenditure by heart rate. ${ }^{19}$ Moreover, any bias in the measurement of energy expenditure should apply equally to all subjects; it is highly unlikely to apply specifically to subjects in the lower thirds of energy intake.

It is therefore reasonable to conclude that the observed discrepancies arose largely from inaccurate estimates of habitual energy intake due to conscious or subconscious changes in normal dietary patterns or underreporting, or both. The discrepancies are unlikely to have arisen from random error as the results closely replicated the previous year's measurements, with no perceptible regression of the initial low measurements towards the mean. Furthermore, we used different investigators in the two studies, which strongly suggests that the bias is not due to the observer but is inherent in the method and the impact of the test on the subject. Bias may be greater than is generally appreciated. Consequently, the seven day weighed record may lose accuracy in an attempt to increase precision. This is supported by evidence from interviews with the subjects after the study, in which they all emphasised that the weighing protocol had interfered with their normal eating behaviour and that they had had difficulty in maintaining motivation, 
particularly in the middle of the measurement period. Having to weigh snacks was named as the most onerous and irritating aspect of the procedure, and subjects admitted having omitted or simplified some measurements.

There was some evidence that subjects who recorded low intakes reported eating fewer snacks than those with high intakes, but the differences were not significant (men, three $v$ four snacks a day; women, three $v$ five snacks a day). Similarly, no obvious differences emerged in the type of foods eaten as snacks by the subjects. The mean energy intake from alcohol, however, was only $2.8(\mathrm{SE} 0 \cdot 7) \%$ which compared with a mean estimate of $6.0 \%$ for the United Kingdom..$^{20}$ Men with low energy intakes reported lower alcohol consumption $(1 \cdot 2(0 \cdot 5 \%)$ of energy) than those with high intakes $(3.5(1.2) \%$ of energy), but there was no significant difference among the women $(2.5(0.9) \% v$ $2.9(1.7) \%$ of energy). As self estimation of alcohol consumption is particularly prone to underreporting ${ }^{21}$ this may have contributed to the energy deficit in some of our subjects.

It is important to note that over half of the people invited to participate in this study declined and that it was most difficult to recruit those subjects who had previously been found to have low energy intakes. The present study was therefore probably weighted in favour of more highly motivated and compliant subjects, and thus the bias is unlikely to be an overestimate of either the frequency or degree of error that would exist in more representative study populations. Such bias could generate seriously misleading associations and conclusions in epidemiological studies as the invalid results are at the extreme of the range and hence may exert a powerful effect on regression analyses. Bias could be compounded if poor compliance in assessing food intake was correlated with known variables of health risk such as excess weight, poor quality of diet, low socioeconomic status, or a profligate lifestyle including smoking and alcohol consumption.

Furthermore, the errors in estimating food intake are unlikely to be specific to the current study or to the larger Northern Ireland diet and health study, arising from inexact application of the seven day weighed intake technique. The technique was rigorously applied by trained investigators who maintained a high level of contact with their subjects. Moreover, the Northern Ireland diet and health study was regularly scrutinised by an independent panel of nutritional experts. Thus other studies in which intake may be measured less rigorously will probably be equally prone to biased underreporting of food intake. This conclusion is supported by a recent study of the habitual food intake of female university staff and students assessed by three to five day food journals, which found that true energy requirements were underestimated by $23 \%$ or $2 \cdot 27 \mathrm{MJ} / \mathrm{day} .22$

Thus it is important to consider possible ways to identify biased food records and the interpretative implications of editing data sets to exclude such data. One obvious approach is to use the physiological principles governing energy expenditure to exclude values below a predetermined threshold (for example; $1 \cdot 35 \times$ basal metabolic rate). This cut off point can be used to identify mean intakes of a group that are unrepresentative of long term habitual intake. It can also be used as a cut off for individual values; in this study nine values fell below this cut off value. It should be recognised, however, that although the individual values are unrepresentative of habitual intake, they may partially arise from the known imprecision $( \pm 9 \%$ in this study) of weighing dietary intake for seven days and do not necessarily imply false recording in any given subject.
Unfortunately the small numbers in this study did not provide definitive markers for subjects likely to provide biased estimates of intake. The observed tendency for obese subjects to diet or underreport intake, or both, during the measurement period ${ }^{+}$was confirmed in this study. Underestimation of food intake, however, was also apparent in both moderately overweight and normal weight subjects. Similarly, though there was some indication that subjects of lower socioeconomic status might be more prone to underrecording, this did not reach significance, and biased records were apparent across the range of socioeconomic groups.

Further studies are in progress to try to identify correlates of underreporting and to eliminate underreporting by improving the methods used. In view of the discrepancies observed in th:s study an independent check on the validity of data on food intake should be considered for incorporation. into future studies of diet and health; the doubly labelled water test is too expensive and complex to be used as a routine check. Alternative means of independently cross validating food intakes are available $e^{1}$ and have shown serious non-compliance in dietary reporting by obese subjects ${ }^{23}$ and, in common with the results presented here, in some randomly selected subjects (S A Bingham, personal communication).

In the absence of simultaneous validation the results of epidemiological studies of nutrition should be interpreted and evaluated with caution. At the very least, apparently low food intakes should be treated with considerable scepticism.

This work was supported by the Department of Health and Social Services.

1 Bingham SA. The dietary assessment of individuals; methods, accuracy, new techniques and recommendations. Nutrition Abstracts and Review 1987;57: $705-42$

Southgate DAT Obese deceivers? Br Med f 1986;292:1692-3.

3 Kaldor J, Clayton D. Latent class analysis in chronic disease epidemiology. Stat Med 1985;4:327-35.

4 Prentice AM, Black AE, Coward W'A, et al. High levels of energy expenditure in obese women. Br.Med f 1986;292:983-7.

5 Barker ME, McClean SI, McKenna PG, et al. Diet, lifestyle and health in Northern Ireland. Coleraine: University of Ulster, 1989

6 Garrow JS. Treat obesity seriously: a clinical manual. London: Churchill Livingstone, 1981

7 Office of Population Censuses and Surveys. Classification of occupations. London: HMSO, 1980

8 Metropolitan Life Insurance Company, New York. Metropolitan height and weight tables. Statistical Bulletin of the Metropolitan Life Insurance Company 1983;64:2-9.

9 Paul AA, Southgate DAT. McCance and Widdowson's The composition of foods. London: HMSO, 1978

10 Wiles SI, Nettleton PA, Black AE, Paul AA. The nutrient composition of some cooked dishes eaten in Britain: a supplementary food composition some cooked dishes eaten in Britain: a supplenent

11 Black AE, Prentice AM, Coward WA. Use of food quotients to predict respiratory quotients for the doubly-labelled water method of measuring energy expenditure. Hum Nutr Clin Nutr 1986;40:381-91.

12 Schoeller DA. Measurement of energy expenditure in free-living humans using doubly labelled water. I Nutr 1988;118:1278-89.

13 Coward WA. The doubly-labelled-water $\left(\mathrm{H}_{2}{ }^{\times} \mathrm{O}\right)$ method: principles and practice. Proc Nutr Soc 1988;47:209-18.

14 Prentice $\mathrm{AM}$. Applications of the $\left.\mathrm{H}_{2}{ }^{\mathrm{i}} \mathrm{O}\right)$ technique in free-living adults. Proc Nutr Soc 1988:47:259-68.

15 Coward WA, Prentice AM. Isotope method for the measurement of carbon dioxide production in man. Am $\mathcal{F}$ Clin Nutr 1985;41:659-61.

16 Prentice AM, Coward WA, Davies HL, et al. Unexpectedly low levels of energy expenditure in healthy women. Lancet 1985;i:1419-22.

17 Coward WA, Parkinson SA, Murgatroyd PR. Body composition measurements for nutrition research. Nutrition Research Reviews 1988;1:115-24

18 Food and Agriculture Organisation, World Health Organisation, United Nations University. Report of a joint expert consultation. Energy and Nations University. Report of a joint expert consultaio
protein requirements. WHO Tech Rep Ser 1985; No 724.

19 Livingstone MBE, Prentice AM, Coward WA, et al. Simultaneous measurement of free-living energy expenditure by the doubly-labelled water $\left({ }^{\circ} \mathrm{H}_{2}{ }^{\prime \times} \mathrm{O}\right)$ method and heart-rate monitoring. $A m \mathcal{f}$ Clin Nutr (in press).

20 Brewers' Society. International statistical handbook. London: Brewing Publications, 1988

21 Wilson P. Improving the methodology of drinking surveys. Statistician $1981 ; 30: 159-67$

22 Lissner L, Habicht J-P, Strapp BJ, Levitsky DA, Haas JD, Roc DA. Body composition and energy intake: do overweight women overeat and underreport? Am f Cin Nutr 1989.49:320-5.

23 Wornold I, Carlgren ( 3 , Krotkiewski M. Energy expenditure and body composition during weight reduction in hyperplasic obese women. $A m \mathcal{J}$ Clin Nutr 1978;31:750-63.

Accepted 3 fanuar 1990 